\title{
Reform of Basic Chemistry Experiment Course for Cultivating Creative Talents
}

\author{
Boquan Jiang, ${ }^{*}$ Zhengping Cheng, Lijuan Wan, Yang Shu, Ting Liu \\ Department of Biology and Chemistry \\ Institute of Science \\ Nanchang University College of Science and Technology, \\ Nanchang, Jiangxi, 330029 \\ China \\ *Corresponding author: jbq_win@163.com , mobile phone number: 13397080986
}

\begin{abstract}
Cultivating creative talents is the target of the university education. Reforming the basic chemistry experiment course is one of the important ways to realize the target. At present, the reform of basic chemistry experiment curse are being widely carried out in China's universities. Several measures are proposed to guarantee the reform of basic chemistry experiment to be gone with a swing in this paper. Those measures involve setting up the advanced education idea, establishing a good experimental teaching team, building open teaching mode of basic chemistry experiment, establishing scientific comprehensive evaluation system and establishing perfect operational mechanism and management mode. The detail descriptions of each measure are given based on the practical situation of the college.
\end{abstract}

Keywords- Reform; basic chemistry experiment; cultivating; creative talents; reform of higher education

\section{INTRODUCTION}

The basic chemistry experiment (BCE) course is one of the important basic courses in universities. The BCE includes inorganic chemistry experiment, organic chemistry experiment, physical chemistry experiment and analytic chemistry experiment curses. In some universities, inorganic chemistry experiment and analytic chemistry experiment are combined into one course, called university chemistry experiment. This course is opened for many majors such as chemistry, chemical engineering and technology, applied chemistry ${ }^{*}$, biologic engineering*, biologic technology ${ }^{*}$, pharmaceutical engineering*, polymer materials and engineering*, food engineering, material science and engineering, environmental engineering*, water supply and drainage ( the "**” marked are the majors opened in the author's college), and so on. The students can obtain chemical knowledge, operation skills, beginning ability, scientific experimental and research method, and increase their environmental protection and safety awareness through the study of the BCE course. With the in-depth development of China's higher education, cultivating students' innovation spirit and innovation ability is one of the important goals of the BCE course reform. American university teaching method focuses on induction, analysis and comprehensive, independent thinking and innovation ability but lacks attention to solid foundation. Compared with America, traditional China's teaching method focuses on deduction, reasoning, rigorous, serious, solid foundation but lacks attention to cultivating student's innovation consciousness [1, 2, 3, 4] . The important goal of our reform should adopt foreign good points and avoid his shortcomings and pay more attention to cultivating the innovation type talents based on the solid foundation. The following presents our opinions on how to conduct the reform of basic chemistry experiment course for cultivating creative talents.

\section{SetTING UP THE ADVANCED EDUCATION IDEA}

For cultivating the creative talents, the advanced education idea should be set up instead of the traditional education concept $[5,6,7]$. The advanced education idea requires us to (i) set up the education idea on the coordinated development of giving priority to students, knowledge-transference, ability training and quality improvement; (ii) set up the new experiment teaching idea on taking ability training as the core concept of experimental teaching; (iii) establish the experimental teaching system which is favor of cultivating students' practice ability and innovation ability; (iv) establish an excellent experiment teaching team to meet the needs of the modern experimental teaching; (v) construct a good experiment teaching environment with advanced equipment and instrument, resource sharing and open service and (vi) establish a modern efficient management mechanism. According to the advanced education idea, the traditional experiment teaching method with the "taking teaching as the center" should be changed and the new experimental teaching modes with "taking students as the main body while teacher as the guider" should be advocated. The teachers and administrative staff should conduct a bold transfer from the " teaching as center " into the "learning as center", insist on the coordinated development of knowledgetransference, ability training and quality improvement, pay attention to the cultivation of student's exploring 
spirit, scientific thinking, practical ability and innovation ability, and implement the advanced education idea and the new experimental teaching concept consistently throughout the BCE course.

\section{ESTABLISHING A GOOD EXPERIMENTAL TEACHING TEAM}

For cultivating the creative talents, a good experimental teaching team should be established. Having a good experimental teaching team is the important guarantee to make the experimental teaching reform smoothly carried out $[8,9]$. In the curriculum and personnel arrangement, the elder teachers with rich practical experience and title of a senior professional post and the younger $(\mathrm{PhD})$ teachers having new idea and strong ability should be given priority to considered. The team requires a reasonable faculty structure in age, professional tittle and professional degree according to the practical situation of different universities. In the light of our practical conditions, the team members composite of one professor, two associate professors, 4 lectures and one elder technician. The team includes 3 members with age of more than 50 years old, 2 members with age of between $30-40$ years old and 3 members with age of below 30 years old. In the team, the numbers of member with bachelor's degree, master's degree and doctor's degree are 2, 4 and 1, respectively. From the view of the structure of age and professional tittle, the team composition is reasonable, but the number of young teachers has a larger proportion. Although the young teachers deeply love their jobs, work with high enthusiasm and have certain scientific research abilities, they lack experimental teaching experience due to short teaching time. Therefore, effective measures should be taken to improve their experimental and scientific levels, open their field of vision and increase their research ability of the experiment teaching reform, except their continuous themselves-improvement in the teaching practice. The measures involve visiting and learning from the other universities, attending the national short-term training class on the BCE teaching and going to some domestic famous universities for a short-time training on the BCE, during the summer and winter vacations. Furthermore, the university provides opportunities for their obtaining higher professional degree in a planned way.

\section{BUILDING OPEN TEACHING MODE OF BASIC CHEMISTRY EXPERIMENT COURSE}

For cultivating the creative talents, an open teaching mode of BCE should be built.In order to increase the student's independent design, application and innovation ability to reflect the education idea of "with the students as main body", it is imperative to build an open teaching mode of basic chemistry experiment [10, $11,12]$. The open experimental teaching means that the students independently complete their whole experiment procedure through their own thinking and exploration under the instruction of teachers. This mode is an important way to develop the student's potentials, increase the student's scientific quality and cultivate the student's innovation ability. At present, most of the experiment projects of BCE are compulsory and verified projects in our college. The laboratories are only opened to student's professional experiment, graduation thesis and extracurricular scientific and technologic activities, which is not be included in the teaching content and evaluation scope of BCE. So it is urgent for us to implement open teaching of BCE. We have planed, step by step, to open multi-level open experiments including applied, comprehensive, design and innovative experiments. In this semester, the course of organic chemistry experiment is being opened to the students. During the open experiment process, the students are required to freely select the experiment project prepared by teachers and independently finish the project by various steps, such as independent literature review, making design scheme, predicting needed chemicals and instruments, establishing experimental device, starting work, data treatment, writing small essays, reporting the experiment by PPT document, etc.. Mutual discussions and exchanges between the students and between the students and teachers are advocated. The laboratories provide the experimental place, time and instruments \& chemicals for the students to ensure the open experiment smoothly conducted. The orderly and standardized multi-level experiments can effectively promote the student's selfdirected learning, cooperative learning and creative learning abilities. Recently, the open teaching modes of BCE are being researched and explored in many universities and colleges. Our team will do our best to implement the open teaching of BCE course with innovative and unique characteristics.

\section{ESTABLISHING SCIENTIFIC COMPREHENSIVE EVALUATION SYSTEM}

For cultivating the creative talents, it is important to establish a set of scientific, reasonable and operational comprehensive evaluation system for the BCE course[13, 14, 15].

To ensure good experimental teaching quality, the comprehensive evaluation system involves four respects as follows.

\section{i. Mark at ordinary times}

The mark at ordinary times accounts for $60 \%$ of the total grades, including preview (10\%), ideological quality concerned with energy conservation and emissions reduction, environmental protection, safety, 
hygiene, taking good care of public property (10\%), operation (25\%) and experimental report (15\%).

ii. Theory assessment

In the light of the decoupling phenomenon of theory and practice in part of the students, the theory examination is added on the basis of the existing assessment. The content of the theory examination mainly involves the purpose and principle of each experiment, problem analysis, data processing method, device structure, the equipment, principle and purpose of different unit operation, etc.. The purpose of the theory examination lies in cultivating the student's learning style of theory combined with practice. The theory examination method can be conducted by that the teachers prepare the note type questions in advance and then the students temporarily extract the questions and give an answer during the examination. (10\%).

iii. Operation assessment

In order to check the student's abilities of mastering basic operation skills, the operation examination is carried out at the end of the course. The operation examination can be conducted by that the teachers prepare the note type questions in advance and then the students temporarily extract the questions and show their experimental performances on the scene. The grade of operation examination is $10 \%$ of the total grades.

iv. Open experiment assessment

Open experiment can arouse the enthusiasm of students' autonomous learning, cultivate students' ability to use knowledge to solve practical problems and improve students' innovative consciousness and ability level in scientific research and application. The assessment involves literature searching, project design, steps determination, operation skill, data processing, writing experiment report, etc. The open experimental projects with certain interest, comprehensive, practice and novelty are given by teachers for students to choose. Most of the principle and manipulation concerned in each open experimental project have already learned by students. The key of assessment lays emphasis on experimental scheme design and experimental process and mainly examines students' comprehensive ability to use knowledge to independently complete a open experiment. The open experiment results account for $20 \%$ of the total grade.

\section{ESTABLISHING PERFECT OPERATIONAL MECHANISM AND MANAGEMENT MODE}

For cultivating the creative talents, a perfect operational mechanism and management mode ( OMMM) are required to be established [16, 17, 18]. A perfect OMMM should involve standardized laboratory management system and network teaching management system. The standardized laboratory management system involves a set of integrated laboratory management regulations and rules from the view of experiment operation, safety and health, environmental protection, chemicals and equipment management, energy conservation and emissions reduction, open experiment, etc. In our college, the regulations and rules include "Laboratory safety and health management stipulation of Nanchang university college of science and technology", "Laboratory equipment compensation rules of Nanchang university college of science and technology ", "Dangerous goods management regulations of Nanchang university college of science and technology", "Student experiment rules and regulations of Nanchang university college of science and technology", "Basic chemistry experiment rules of basic chemistry laboratory of Nanchang university college of science and technology", "Waste disposal regulations of basic chemistry laboratory of Nanchang university college of science and technology", "Laboratory experiment accident emergency treatment rules of basic chemistry laboratory of Nanchang university college of science and technology”, "Open laboratory management stipulation of basic chemistry laboratory of Nanchang university college of science and technology" and "Teachers' responsibility on open laboratory management of basic chemistry laboratory of Nanchang university college of science and technology”. Teachers and students must strictly obey these rules and regulations to make sure that the experiments are smoothly carried out. The network teaching management system is mainly to establish the network experimental teaching and laboratory management information platform in order to realize auxiliary teaching and network management, namely video or multimedia auxiliary teaching. In addition, the effective measures, such as developing the management mechanism to motivate students to conduct self-directed learning, creating good personalized learning environment for the students, establishing the scientific evaluation mechanism of experimental teaching, leading teachers actively to take part in reform and innovation, setting up open experimental teaching policy and improving experiment teaching quality guarantee system, are required to be taken to ensure the experiments to be gone on wheels.

\section{CONCLUSIONS}

Through the implementation and practice of BCE course reform by taking the proposed measures in the text, good results have been acquired. The teachers set up the advanced education idea in their minds and actively participated in the BCE reform activity. The teachers' professional level and teaching quality were greatly improved. The younger teachers increased their 
scientific and experimental abilities. The experimental environment had a great improvement.The students insisted on autonomic learning and their innovation consciousnesses and abilities have obviously enhanced, which is conductive to their future study and work.

\section{ACKNOWLEDGMENT}

This subject comes from " the Projects on Demonstration Laboratory Construction " financially supported by Nanchang University College of Science and Technology.

\section{REFERENCES}

[1] Wang Shuying, Zhang Xiangfei and Guo Baoguo.”Cultivating personnel with innovation spirit by reforming the basic chemistry experiment in universities”.. Journal of Shangqiu Teachers College, 2010, Vol. 26, issue 3, pp..38-140.

[2] Sun Degong, Li Jianying, Huang Puxuan, at.al...'Reform on teaching content and method of four basic chemistry experiments”. Laboratory teaching, 2002, issue 4, pp.28-29,32.

[3] Xia Jingfen, Lin Jianyuan, Tang Li and Ying Ming. "Reforming basic chemical experiment teaching model to cultivate high quality talents”. Experimental Science and Technology, 2008, Vol. 6, issue3, pp.:87-89.

[4] Li Xiulin, Cai Jiqing, Zeng Xiuqing, Zhao Huarong and Fu Chunlin. "Adhering to the people-centered to well do basic chemistry experiment teaching “.University Chemistry, 2011, Vol. 26, issue2, pp.:32-33,37.

[5] He Jianfeng, Wang Tao, Chen Chuanbing, Zhu Chenchen. "Study on the Modernization of the experimental teaching system for the fundamental chemistry". Experimental Science and Technology, 2010,8, issue 5, pp.84-85.

[6] Li Guoxiang, Cai Yin. "Exploration and practice of university chemistry course construction and teaching reform of Engineering colleges and universities”. Chinese Science and education, 2005, issue6, pp. 17-19.

[7] Ouyang Yuzhu, Chen Xiaodong, Peng Xiaochun and Wang Yingchun. "Research on Teaching of fundamental chemistry experiment based on green chemistry concept". High Education in Chemical Engineering, 2010, issue 2, pp.64-67.

[8] Guo Xiulan, He Tingyu, Zeng Manzhi, Xu Li and Luo Zhigang. "Experience and suggestion to improve quality of the teaching of fundamental chemistry experiment “. Guangdong Chemical, 2009, Vol. 36, issue 193, pp. 204-206.

[9] Li Hongmei, Lu Jiang and Wang Xianfeng. "Practice and summary of college basic chemical experiment teaching". University Chemistry, 2011, Vol. 26, issue 5, pp.39-42.

[10] Li guoxiang, Li songbo. "Study and exploration of open teaching mode of basic chemistry experiment". Inner Mongolia petrochemical industry, 2007, issue 1, pp.21-22.

[11] Xu Yaqin, Fu Ying. "Research and exploration of openchemistry experiments”. Experimental technology and management, 2007, issue 2, pp. 14-15.
[12] Yang Liuqing. “Thoughts about integrating the scientific research progress into the teaching of basic chemistry experiment”. The science educ, 2012, issue3, pp. 123-124.

[13] Wang Xueying, Xu Xiaoxing and Li Qiaoyun. "The construction of system of basic chemical experimental teaching and evaluation based on the applied talents training “. .Journal of Changshu Institute of Technology, 2008, issue12, pp. 120-122.

[14] Liu Kui, Wang Jianmin and Sun Hua. "Exploration and research on establishing a comprehensive evaluation system of the experimental results”. GAO XIAO SHIYANSHI GONGZUO YANJIU, 2010, Vol. 104, issue2, pp. 32-33,77.

[15] Cui Hongshan, Xiong Ya,nlin. "Exploration and research of evaluation system of basic chemistry experiment teaching". Journal of Anhui University of Science and Technology(social science edition),2007, Vol. 9, issue4, pp. 85-88.

[16] Yan Liangguo, Wang Jingang, Wei Qin.”Practice and exploration of basic chemistry teaching based on green education mode”. Chemistry education, 2008, issue6, pp. 66-68.

[17] Wang Guirong, Yang Gengshe. "Research on university laboratory management system reform based on the innovation education idea”.Technology and innovation management, 2008, issue6, pp. 559-561.

[18] Deng Changai, Liu Huijun, Chen Zhongqing, Xia Liangshu and Wang Xiaojuan. "Application of multimedia technology in the teaching of basic chemistry experiments". China Modern Educational Equipment, 2010, issue 13, pp. 65-67. 